\title{
PELATIHAN PEMANFAATAN KALENG BEKAS MENJADI PRODUK BERNILAI EKONOMI PADA GURU SEKOLAH LUAR BIASA DI DKI JAKARTA
}

\author{
Menul Teguh RIYANTI \\ Fakultas Seni Rupa dan Desain, Universitas Trisakti \\ Email: menulsukarno@yahoo.com
}

\begin{abstract}
The Faculty of Fine Arts and Design of Trisakti University carries out Community Service in collaboration with Kadin as a partner of 20 special school teachers in a special area of the Capital City of Jakarta with skills training in processing used paint cans into economic value products. Participants are trained to clean and dye used paint cans of $5 \mathrm{~kg}$ size and become economic value products. The objectives of this activity are: 1) participating teachers have the skills to process waste into economic value goods, 2) participating teachers can teach these skills to their students, 3) the quality of the environment in DKI Jakarta can be better through the touch of school teachers extraordinary and their students. The results of the Training on the Utilization of Used Cans into economic value-selling products for special school teachers in DKI Jakarta provide knowledge / skills and knowledge that can be developed independently individually or in groups.
\end{abstract}

Keywords: Skills training, used cans, economic value products.

\begin{abstract}
ABSTRAK
Fakultas Seni Rupa dan Desain Universitas Trisakti melaksanakan Pengabdian Kepada Masyarakat bekerja sama dengan Kadin sebagai mitra sejumlah 20 orang guru sekolah luar biasa dilingkungan daerah khusus Ibu Kota Jakarta dengan pelatihan keterampilan mengolah limbah kaleng cat bekas menjadi produk bernilai ekonomi. Peserta dilatih membersihkan dan mewarnai kaleng cat bekas ukuran $5 \mathrm{~kg}$ dan menjadi produk bernilai ekonomi. Tujuan kegiatan ini adalah:1) para guru peserta memiliki keterampilan mengolah limbah menjadi barang yang bernilai ekonomi, 2) para guru peserta dapat mengajarkan keterampilan ini kepada murid-muridnya, 3) kualitas lingkungan di DKI Jakarta dapat menjadi lebih baik melalui sentuhan para guru sekolah luar biasa dan anak-anak didiknya. Hasilnya dari Pelatihan Pemanfaatan Kaleng Bekas menjadi produk bernilai jual ekonomi pada guru sekolah luar biasa di DKI Jakarta memberikan bekal wawasan/pengetahuan dan keterampilan yang dapat dikembangkan secara mandiri secara individu maupun berkelompok.
\end{abstract}

Kata kunci: Pelatihan keterampilan, kaleng bekas, produk bernilai ekonomi. 


\section{PENDAHULUAN}

Kelestarian lingkungan dan kreativitas merupakan dua hal yang menjadi basis program kegiatan ini. Jakarta dengan kepadatan penduduk 13.667 jiwa per km2 memproduksi sampah sebanyak 7.896 ton setiap hari (http://m.kabar24.com). Sesuai dengan ketentuan yang ditetapkan pada Pasal 5 UU Pengelolan Lingkungan Hidup No. 23 Tahun 1997, bahwa masyarakat berhak atas lingkungan hidup yang baik dan sehat. Untuk mendapatkan hak tersebut, pada Pasal 6 dinyatakan bahwa masyarakat dan pengusaha berkewajiban untuk berpartisipasi dalam memelihara kelestarian fungsi lingkungan, mencegah dan menanggulangi pencemaran dan kerusakan lingkungan. Terkait dengan ketentuan tersebut, dalam UU No. 18 Tahun 2008 secara eksplisit juga dinyatakan, bahwa setiap orang mempunyai hak dan kewajiban dalam pengelolaan sampah. Dalam hal pengelolaan sampah Pasal 12 dinyatakan, setiap orang wajib mengurangi dan menangani sampah dengan cara berwawasan lingkungan (http://thesains.wordpress.com).

Limbah kaleng cat dengan ukuran $5 \mathrm{~kg}$ akan memberikan dampak negatif jumlah volume sampah yang tinggi tidak terkelola dengan baik penyebab gangguan kesehatan, menurunkan kualitas lingkungan, dan estetika lingkungan. Pemanfaatan kembali secara langsung misalnya dengan membuat produk baru yang berbahan baku limbah atau barang bekas. Pemanfataan tersebut menerapkan prinsip-prinsip Re-use (memakai kembali), yaitu sebisa mungkin memilih barang-barang yang bisa dipakai kembali, dan Recycle (mendaur ulang), yaitu memaksimalkan pemakaian kembali material dengan teknologi daur ulang melalui industri non-formal dan industri rumah tangga yang memanfaatkan sampah menjadi barang lain yang dapat digunakan lebih lanjut.

Persoalan sampah khususnya di Jakarta menjadi masalah yang sangat pelik dan sangat sulit untuk dipecahkan. Kurangnya kesadaran masyarakat dalam menjaga lingkungannya adalah salah satu hal yang paling dominan dalam menyumbangkan berbagai masalah sampah di perkotaan tersebut. Salah satu barang bekas pakai yang sulit terurai secara alami adalah wadah berbahan kaleng. Oleh karena itu, kaleng-kaleng bekas (misalnya kaleng bekas kemasan cat), biasanya digunakan kembali (reuse) sebagai wadah atau fungsi yang lain. Fakultas Seni Rupa dan Desain dalam hal ini adalah Program Studi Desain Komunikasi Visual, memiliki kompetensi berkaitan dengan teknik pewarnaan yang menonjolkan aspek estetika. Dengan bekal keilmuan tersebut, Program Studi Desain Komunikasi Visual akan memberikan pelatihan dengan tema "Pelatihan Pemanfaatan Kaleng Bekas Menjadi Produk Bernilai Ekonomi". Melalui pelatihan ini sasaran akan memahami cara memanfaatkan kaleng bekas menjadi pot tanaman dengan memberikan sentuhan warna yang menarik. Sebagai sasaran pelatihan adalah bapak libu Guru dari Sekolah Luar Biasa di wilayah Jakarta Barat. Program Pengabdian Kepada Masyarakat bekerjasama dengan KADIN dan Universitas Trisakti melakukan perjanjian kerjasama dengan Sekolah Luar Biasa dalam Lingkup di Jakarta

1. Minimnya lahan penghijauan di Jakarta sehingga diperlukan media tanam khusus agar masyarakat tetap dapat menanam berbagai jenis tanaman.

2. Tersedianya kaleng bekas serta sumber daya manusia yang belum dimanfaatkan dengan maksimal.

Adapun tujuan dari kegiatan Program Pengabdian Kepada Masyarakat ini adalah:

a. Mengurangi limbah kaleng bekas dengan cara memanfaatkannya menjadi produk yang bermanfaat.

b. Memberikan bekal wawasan/pengetahuan dan keterampilan yang dapat dikembangkan secara mandiri oleh target sasaran, baik secara individu maupun berkelompok.

c. Mengembangkan potensi sumber daya manusia khususnya pada tingkat generasi muda.

d. Membuka peluang alternatif kegiatan usaha mandiri. 
Program Pengabdian kepada Masyarakat ini akan memberi manfaat kepada target sasaran berupa:

a. Turut membantu pemerintah pada tingkat Kelurahan dan Kecamatan dalam memberdayakan kemampuan masyarakat, khususnya para wanita dalam menciptakan alternatif kegiatan yang dapat memberikan nilai ekonomis.

b. Menambah pengetahuan dan kesadaran bagi para remaja-dewasa mengenai pengolahan sampah khususnya limbah kaleng bekas yang dihasilkan dalam keseharian masyarakat perkotaan.

c. Bagi Universitas Trisakti, khususnya Program Studi Desain Komunikasi Visual Fakultas Seni Rupa dan Desain Universitas Trisakti merupakan realisasi kepedulian dalam rangka pendidikan seni dan desain bagi masyarakat luas.

\section{METODE PELAKSANAAN}

Pelaksanaan Program Pengabdian Kepada Masyarakat ini dilakukan oleh 20 orang Bapak/lbu Guru Sekolah Luar Biasa dalam beberapa tahapan yaitu pertama melakukan survey ke sekolah luar biasa menemui para bapak/ibu guru ketrampilan bagaimana agar para murid mudah menerima pelatihan dalam mengambar serta mewarnai dengan cat minyak.

Kegiatan dilakukan dengan tahapan:

1. Pelatihan dengan metode ceramah, diskusi, dan tanya jawab mengenai materi pelatihan, dimulai dengan pengenalan terhadap alat, bahan, dan media yang digunakan.

2. Penyuluhan tahapan kerja dalam pemanfaatan kaleng bekas

3. Praktik pembuatan kaleng bekas dengan desain yang telah disiapkan oleh para peserta pelatihan, dengan bimbingan secara langsung dari para instruktur untuk mengarahkan peserta dalam setiap tahapan pelaksanaan.

4. Pengembangan elemen warna yang dipilih oleh peserta pelatihan.

5. Diskusi dan evaluasi hasil karya peserta pelatihan.

Gambaran Umum Kegiatan.

Kegiatan berlangsung di Fakultas Seni Rupa dan Desain Universitas Trisakti, Jalan Kyai Tapa no 1 Grogol Jakarta Barat. Fakultas Seni Rupa dan Desain Universitas Trisakti mempunyai 6 (enam) Program Studi terdiri dari Program Studi Desain Interior, Desain Produk, Desain Komunikasi Visual, Fotografi, D3DKV dan Magister Desain Produk.

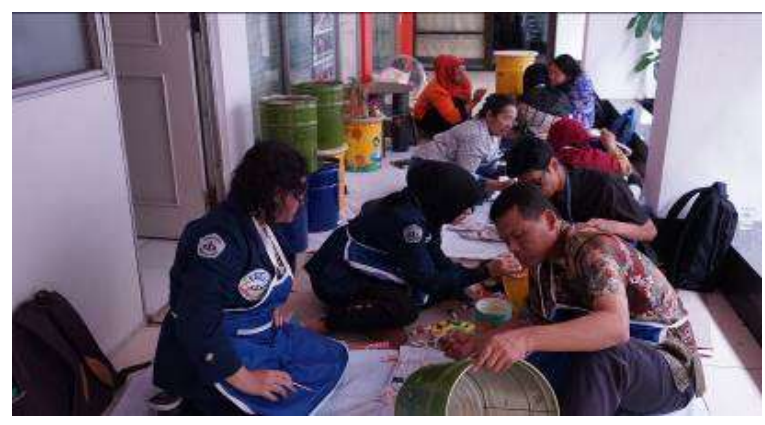

Gambar 1. Lokasi Pelaksanaan PKM, Fakultas Seni Rupa dan Desain Universitas Trisakti

\section{METODE PELAKSANAAN}

Kegiatan pelatihan diikuti oleh para Bapak/ Ibu Guru Sekolah Luar Biasa di lingkungan Jakarta. Peserta program ini berjumlah 20 (dua puluh) orang, dengan rentang usia $30-50$ tahun. Tingkat pendidikan para peserta adalah Sarjana Pendidikan, dengan tingkat pendidikan terbanyak adalah Sarjana. Tim pelaksana adalah tenaga pengajar di Fakultas Seni Rupa dan Desain Universitas Trisakti, berjumlah 4 
orang terdiri dari sebagai penanggung jawab program berbasis keilmuan Desain Komunikasi Visual dibantu oleh satu dosen dengan ke ilmuan yang sama didukung oleh 2 mahasiswa semester lima yaitu Ghaisani dan Tabitha. selain itu dibantu oleh 1 (satu) orang tenaga penunjang saudara Dwijayanto sebagai petugas dokumentasi dan sekretariat. Sinergi keilmuan Desain Komunikasi Visual mendukung pemahaman terhadap proses teknik desain dua dimensi, dengan didukung atas pemahaman terhadap material bahan bekas untuk produk yang dibuat.

\section{HASIL DAN PEMBAHASAN}

Produk yang dihasilkan oleh 20 orang peserta tersebut adalah aplikasi warna pada gambar di kaleng bekas. Satu kaleng dikerjakan 2 orang peserta. Dari hasil kerja tersebut, dihasilkan 10 kaleng bekas yang menjadi produk fungsional bernilai ekonomi. Dari materi dan peralatan tersebut, para peserta mempelajari teknik dasar pengecatan untuk dasar cat sehingga limbah kaleng bekas dapat berubah dari yang terkesan kotor menjadi lebih menarik. Kemudian untuk tahap selanjutnya memberikan warna pada ilustrasi di kaleng tersebut. Perbedaan yang dapat dilihat dari individu atau kelompok terletak pada eksekusi pengerjaan.

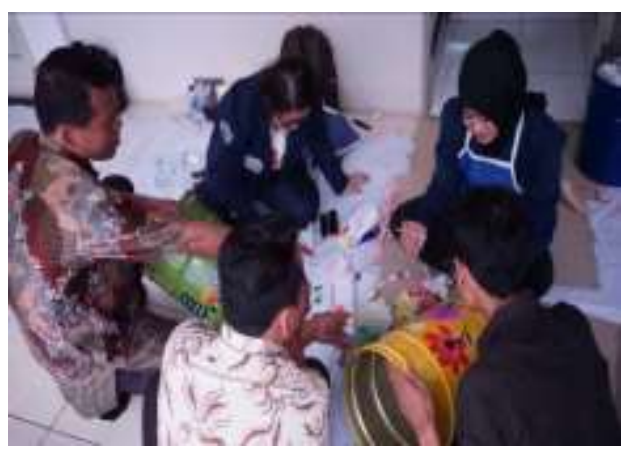

Gambar 2 Kegiatan dilaksanakan Fakultas Seni Rupa dan Desain Universitas Trisakti

\section{PELAKSANAAN}

Jadual kegiatan dilaksanakan pada

Senin I 8 November 2018, pukul 10.00 - 13.00 WIB.

Tujuan program PKM, konsep pelatihan, materi pengenalan bahan dan langkah kerja disampaikan oleh Dr Menul T. Riyanti, SSn, MPd sebagai koordinator pelaksana.

Bahan dan alat yang digunakan adalah: (a) Kaleng bekas, (b) Cat akrilik/cat minyak, (c) Kuas, (d) Minyak tanah, (e) Lap, (f) Celemek.

Untuk kemudahan dan keterbatasan waktu, kaleng bekas telah diberi warna dasar, dibekali modul gambar sederhana untuk kemudian menjadi media kreativitas .Proses pelatihan dimulai dengan menunjukkan proses pewarnaan oleh instruktur. Pewarnaan menggunakan cat akrilik yang diaplikasikan menggunakan kuas pada modul gambar.

Setelah penjelasan teknis dari instruktur, peserta pelatihan memberikan pewarnaan pada kalengkaleng bekas yang disediakan 

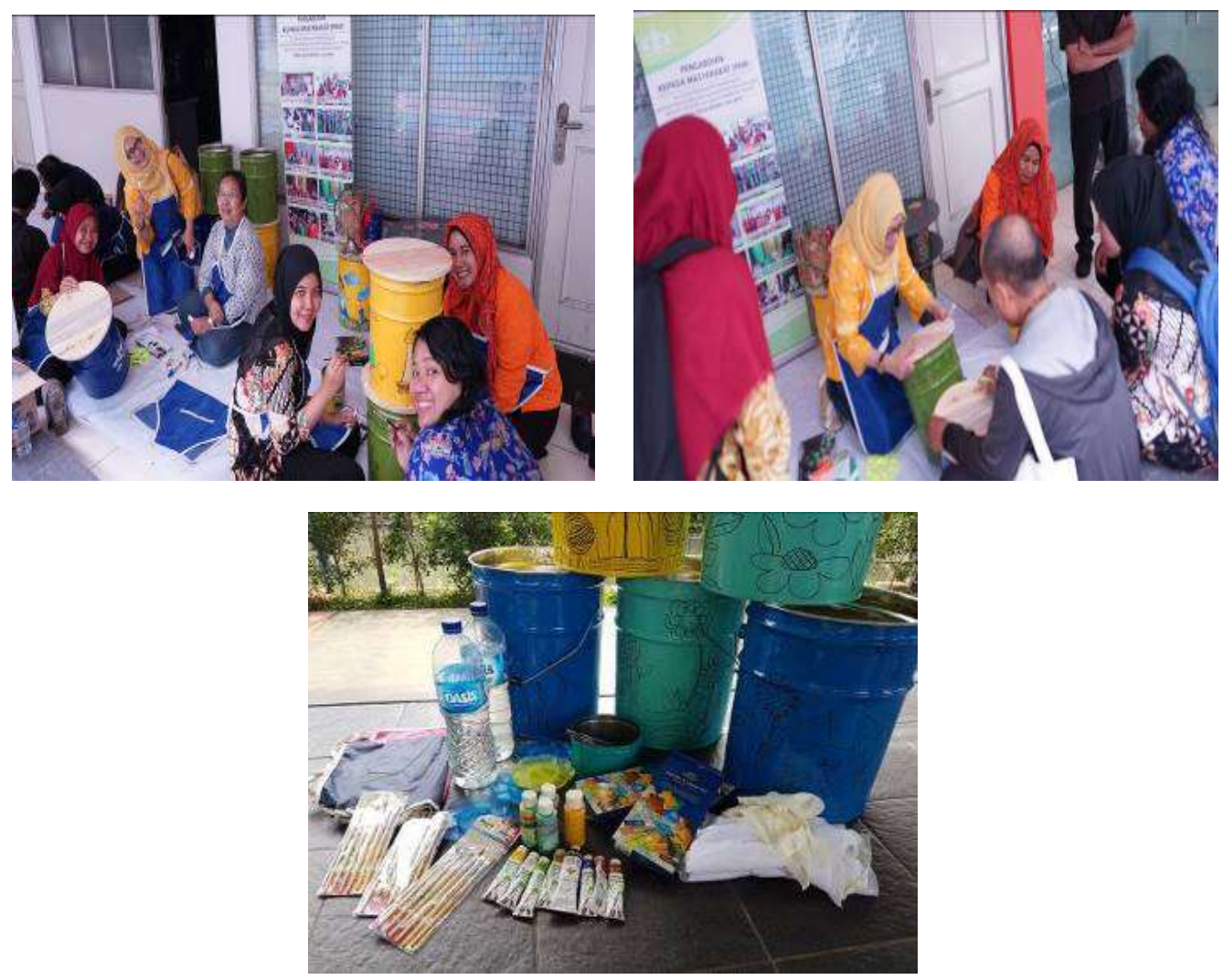

Gambar 3. Bahan dan Alat yang Digunakan

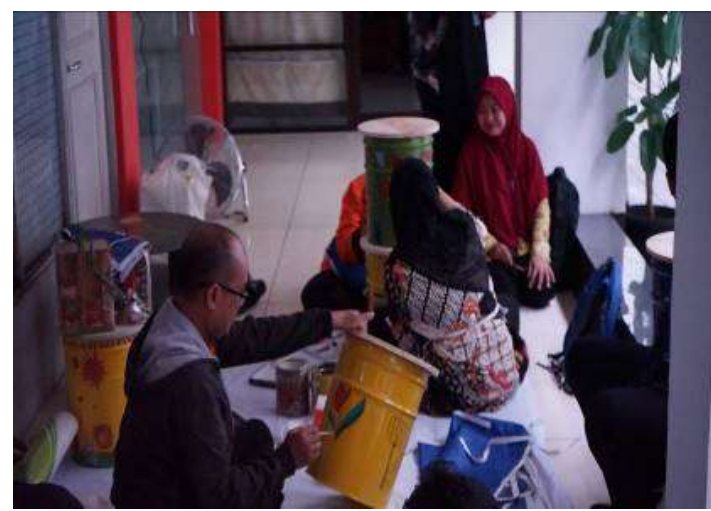

Gambar 4. Proses Pewarnaan Kaleng Bekas

Sumber: Dwijayanto 2018

Dari pemantauan hasil kerja yang dilakukan oleh para peserta, menunjukkan suatu gejala umum bahwa keterampilan perlu diajarkan secara sistematis. Pemecahan masalah melalui contoh/bantuan teknis per kasus di setiap tahapan kerja perlu dilakukan para instruktur sehingga diperoleh hasil yang sesuai dengan yang diinginkan. Hampir seluruh peserta memperlihatkan kinerja yang baik. Secara teknis, peserta mengalami hambatan dalam mengelola kaidah keseimbangan warna dan komposisi pola desain.

Berbagai kesan diberikan oleh peserta yang selain menganggap pelatihan ini cukup sulit tetapi juga menarik untuk dipelajari lebih mendalam karena menarik dan dapat dimanfaatkan untuk mengembangkan kaleng tesebut menjadi tempat duduk. 
Evaluasi Produk Akhir

Setiap kelompok peserta yang terdiri dari 2 (dua) orang mampu mengerjakan proses pewarnaan pada 1 (satu) buah kaleng bekas dengan menggunakan modul desain serta pengembangan warna-warna pilihan sesuai petunjuk pelaksanaan secara verbal dan contoh langsung dari instruktur. Para peserta mencoba membuat tahapan

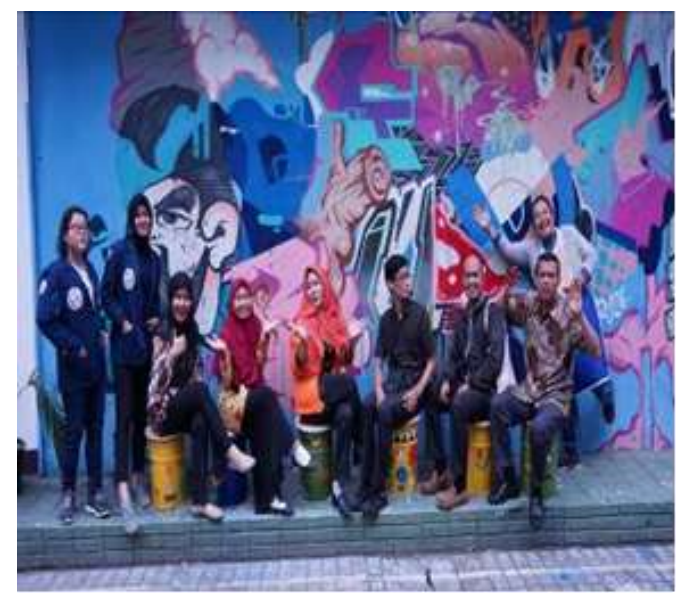

\section{Gambar 5. Peserta Pelatihan dengan Karya Bersama \\ Tim Instruktur dan Mahasiswa FSRD Univ Trisakti \\ Sumber: Dwijayanto 2018}

Penilaian produk didasarkan kepada teknik garapan material. Keragaman hasil kreasi para peserta merupakan hasil yang positif dan sesuai dengan ekspektasi program. Pemilihan dan penentuan warna dan elemen gambar lain sebagai tambahan menjadi hal yang menentukan dalam estetika produk akhir. Secara prosedural semua peserta dapat mengikuti langkah kerja dengan tertib. Selama bekerja para peserta memperlihatkan kemajuan mental kerja, perubahan skill dan pengetahuan yang baik yang ditunjukkan melalui produk akhir. Sikap demikian bukanlah merupakan suatu kekurangan, melainkan menjadi pemicu akan hasil yang lebih baik di masa mendatang.

\section{SIMPULAN}

Secara umum kegiatan pelatihan dalam program Pengabdian Kepada Masyarakat ini telah berlangsung dengan baik dan memenuhi target tujuan dari sasaran. Pelatihan keterampilan membuat kaleng bekas menjadi produk fungsional bernilai estetis merupakan sebuah keterampilan baru bagi para bapak ibu guru SLB atau Sekolah Luar Biasa di wilayah Jakarta Barat, sehingga menjadi sebuah pengalaman baru yang mengesankan bagi target sasaran.

\section{DAFTAR PUSTAKA}

Safanayong, Yongky (2008). Desain Komunikasi Visual Terpadu. Jakarta Arte Intermedia Sihombing, Danton ( 2016). Tipografi dalam Desain Grafis, Penerbit PT Gramedia Pustaka Uama, Kompas Gramedia Building. 